\title{
Reclaiming the heterogeneity of the Arab States
}

\begin{abstract}
Purpose: This paper addresses the clustering of seven Arab States within Hofstede's national culture dimensions, and its implications for international firms targeting the MENA region. We argue that reexamining the Arab States' national cultures can provide interested firms with a better understanding of the differences and similarities between them.
\end{abstract}

Design/methodology/approach: The paper utilized Hofstede's VSM 13 questionnaire to measure the seven Arab States on all six dimensions. The research's translation and methods were overseen by Hofstede and approved before subsequent analysis. In total, 1400 surveys were disseminated to the Arab States, 200 for each country.

Findings: We found evidence that national cultural differences do exist across the Arab States, and discuss implications for international firms wishing to enter or expand in the region.

Research limitations/implications: Because of the chosen research approach, the research results may lack generalisability. As such, the present study can be extended to include more countries to provide a better comparison of different national cultures.

Practical implications: The present study also provides international firms with updated figures for comparison and a better understanding of the region's national culture and its implications and potential for international firms.

Originality/value: The present study is the first attempt to empirically un-cluster Hofstede's original Arab States' sample using both Hofstede's own methodology, thereby negating assumptions of a homogenous Arab national culture and region.

Keywords: Arab States; MENA region; Hofstede; MNC

Article Type: Research paper 


\section{INTRODUCTION}

This paper questions the clustering of several Arab States within Hofstede's national culture dimensions and aims to reexamine their ranking on each individual index. It argues that doing so will establish their national cultural heterogeneity and allow for better profiling and segmenting strategies. The Middle East and North African (MENA) region is home to more than 350 million consumers and as such represents an opportunity for international businesses exploring new and untapped sources of revenue (Mahajan, 2012). Hence, we argue that using Hofstede's cultural theory to reexamine and establish the Arab States' respective national cultures can provide interested firms with a better understanding of their differences and similarities, so as to appropriately adjust their products and services and better serve their consumers.

Hofstede's framework is to a large extent viewed as a paradigm in which his dimensions and the subsequent country scores are used as a taken-for-granted assumption in many fields to explain the influence of culture on human behavior (Sondergaard, 1994). The ability to use national culture to explain aggregate national consumer behavior towards different phenomena is considered useful by many practitioners when planning and executing their marketing, managerial, and segmenting strategies (Singh, 2006). Research indicates that culture incompatibility is a major obstacle to an international firm's success in foreign markets. Cultural differences can act as a barrier, and thus a heightened awareness of and sensitivity to such differences can act as a major organizational resource (Tian and Borges, 2011). Moreover, time constraints and lack of data regarding certain countries has led many researchers to adopt Hofstede's existing paradigm when dealing with cultures, which may be very different from the domestic environment (Clark, 1990). International firms that are able to understand the cultural environment of their target market and develop the capacity to reconcile cultural differences or to exploit them, can acquire a competitive edge in the marketplace (Leung et al., 2005). It is because of the significance of the impact of national culture on the international marketing field, that the present study questions the clustering of the MENA region and the serious implications that this has on interested international firms targeting the region.

There is a need for international firms to develop a solid understanding of target markets to ensure successful market entry, a proactive organizational culture, as well as the adoption and acceptance of their products and services (Takada and Jain, 1991). Hence, identification of the MENA region's various cultures is crucial in helping managers develop successful marketing strategies and operations. This is an important issue since it is often argued that culture can play a deterministic role in the success rates of international firms (Tian and Borges, 2011). As such, the present study extends Hofstede's model by remeasuring Arab States individually according to his dimensions using his latest research instrument, the VSM13 questionnaire. The latest iteration of the questionnaire includes two additional dimensions, which have not been measured in Hofstede's original research investigation regarding the 
MENA region. The new additional dimensions are long term orientation versus short term orientation, and indulgence versus restraint. In fact, Hofstede surveyed only seven Arab States from the MENA region - Kuwait, United Arab Emirates (UAE), Kingdom of Saudi Arabia (KSA), Egypt, Iraq, Libya, and Lebanon. The region had 141 respondents in total; 79 respondents in 1969 and 62 respondents in 1972. After the research, however, IBM chose to erase the raw survey data and destroy all data printouts. The only data left pertained to the entire region as a whole, and consequently Hofstede was in essence forced to treat the region as one cluster (Hofstede, 2001). The MENA region is a heterogeneous region in terms of culture, society, and political institutions. The West is more familiar with its stereotypes than its specificity (Bowen and Early, 2002). Clustering seven Arab States and ignoring all their individual particularities will only reinforce the idea that the region is more or less the same.

The aim of the present study is to address the pitfalls of attributing yesterday's outdated and clustered cultural profile of the MENA region to today's much changed landscape. To address this issue, we first examine the literature on national culture, particularly Hofstede's theory and his dimensions. We then discuss the methodology used to distinguish the seven Arab States from each other and to establish their individual ranking on Hofstede's dimensions. The study then provides empirical evidence to describe the differences between the seven Arab States and as such validate the claim for the region's heterogeneity. Additionally, empirical contributions include the translation and application of an updated version of Hofstede's national culture survey, the VSM 13, to the seven Arab States. Secondly, the VSM 13 survey measures the Arab States on two more dimensions which have not been previously measured before the present study's investigation. Thirdly, the updated figures are used for better comparison and understanding of the region's national culture and their implications in an international business context. Finally, the theoretical contribution of the present study offers empirical evidence that the MENA region's national culture profiles differ on all dimensions and as such the findings are seen as an extension and validation of Hofstede's national culture theory.

\section{NATIONAL CULTURE THEORIES}

Two of the first researchers to apply the concept of national character in social science research and theory were Inkeles and Levinson (1969). They proposed that personalities had commonalties that could be determined and aggregated from a representative sample of the population to represent a unified cultural characteristics. Although Inkeles and Levinson are acknowledged as two of the pioneers of national character, a cited criticism of their proposed dimensions is that they were constructed solely from their review of anthropological and psychological research dating back as early as the beginning of the 20th century, and hence had little empirical significance to the present (Peterson, 2007). It is important to mention that national culture theory is not the only classification available that measures national values (Caprar et al., 2015). For example, Hall (1976) classifies cultures as either high context or low context, in which a low context dimension represents cultures that use explicit communication, 
whereas high context cultures use implicit communication. Hall's paradigm is still prevalent in crosscultural research; however, its disadvantage of having a limited number of dimensions often forces researchers to employ it in conjunction with other national culture frameworks (Van Everdingen and Waarts, 2003).

Empirical validation of the concept of national character was established by Geert Hofstede, who constructed national culture dimensions similar to the ones theorized by Inkles and Levinson (1969). Initially, Hofstede conducted factor analysis from nationally aggregated responses from forty countries, which he later divided into four culture dimensions: 1) power distance 2) uncertainty avoidance 3) individualism/collectivism, and 4) masculine/feminine. In 2001 and 2010, he devised two more dimensions: long term orientation do you need "versus short term orientation"? and indulgence versus restraint (Hofstede, 2011). Whilst highly influential, Hofstede's framework has faced censure in recent years (Beugelsdijk et al., 2017). Many scholars have criticized Hofstede's culture dimensions' framework for being superficial and based solely on IBM (Schwartz, 1994). Moreover, Hofstede's survey mainly consisted of questions measuring work related values such as preferred leadership style, job content, and company related questions (Hofstede, 1994). As such, many have questioned the results of the survey, citing that respondent might have been influenced by the immediate situation and place they were in, thus compromising the reliability of the instrument (McSweeney, 2013). 
Nevertheless, other scholars soon sought to improve Hofstede's quantitative approach to the concept of national culture. One such example is the work of Schwartz (2006), in which he identified universal psychological values collected from a sample of college students and elementary teachers from seventythree countries. Using small space analysis, he identified seven interpretable dimensions in which national cultures differ: intellectual autonomy, effective autonomy, embeddedness, master versus harmony, and hierarchy versus egalitarian commitment (Schwartz, 1994). Schwartz's theory shares the same limitation as Hofstede's with regard to the usage of outdated data, as well as the apparent lack of sample representation ( $\mathrm{Ng}$ et al., 2007).

There are other scholars who have attempted to empirically derive values that are shared universally. A study conducted by Trompenaars and Hampden-Turner(1998) sought to develop his own metrics of national culture, building on both Hofstede's model and Schwartz' to construct seven dimensions. These are based on a survey drawn from 15,000 managers in fifty countries and were used to measure differences in national culture in the workplace. Even though the theory was a combination of dimensions from different theories so as to present a more cohesive view of national culture, it has been criticized for not providing significantly new contributions in relation to the previous models (Patel, 2013). Similar research centered on national shared traits can be found in Inglehart's (2000) World Values Survey (WVS), which covered more than sixty-five countries, making it the largest investigation to be conducted on attitudes, values, and beliefs at that time. The rationale behind the WVS project was the belief that worldwide values were changing and that these changes will impact global economic, political, and social systems. However, Inglehart has been criticized for having contrary presuppositions as well as a simplistic interpretation of the relationship between values and modernity (Haller, 2002). Another national culture model is the Global Leadership and Organizational Behavior Effectiveness (GLOBE) study conducted by House et al. (2004) from 1994 to 1997. The study measured organizational values and cultures, of which they later presented in the form of nine dimensions based on responses from around 17,000 managers from sixty-two different societies. The nine dimensions measured both actual societies (as they were) and perceived values (as they should be) in different cultural settings. The nine dimensions were also criticized for being an amalgam of past research; they were simply constructs derived from other work.

\section{Hofstede's critics}

Proponents of national culture theory adopt deterministic assumptions and collect data from large stratified samples, which are later analyzed objectively and statistically (Williamson, 2002). This approach allows findings to be universally applicable. By defining the country as the unit of analysis, national culture theory has provided cross-cultural and cross-national research with an important mode 
of research and investigation in which comparisons can be made between cultures. The ability to dimensionalize culture helps in creating a basis for future hypothesis which in international marketing and cross-cultural research outweighs its limitations (Smith et al., 1996). Since cultural variables are often difficult to access and expensive to operationalize, it is subsequently understandable why so many studies incorporate the Hofstedian framework in their cross-cultural investigations (Lynn and Gelb, 1996). However, viewing culture through a highly functionalist and positivist approach provides an overly simplistic view of what is otherwise a very complex array of cultural components (BaskervilleMorley, 2005). Although such criticism synthesized from the literature may be in favor of more qualitative approaches to the study of national culture, it should be noted that favoring interpretive descriptors of culture seldom produces generalizable findings. By defining the country as the unit of analysis, national culture theory has provided cross-cultural and cross-national research with an important mode of research and investigation in which comparisons can be made between cultures.

The theory of national culture considers the component of culture to be preprogramed in the minds of all nations (Hofstede et al., 2010 ). Subsequently, regardless of whether the chosen sample were students or businessmen, the prevalent societal norms of the nation would be significant enough to be shared sufficiently by all the nationals of the country in question relative to other countries. Moreover, the theory of national culture acknowledges differences and subcultures found within countries, but does not address them, since the theory is based on the differences between countries rather than within them. As such, the national culture model addresses the variations found between countries, and rankings are used as indicators of how nations differ culturally relative to each other. In our particular case, the problem did not stem from how Hofstede devised his ranking, but rather arose because of his clustering of the Arab world into one cultural unit that clearly suggested that there were no cultural differences between the Arab States. Most critics of national culture theory do not use the same methods or research approach as Hofstede when they criticize his national culture theory, which essentially weakens the validity of their argument since they derive from different research philosophies. We believe that what differentiates our study is that we have used the same research approach and methods as Hofstede used with the Arab States and have found different rankings amongst these countries. Having Hofstede oversee the results of our research has also helped us stay faithful to his original methodology and confirm their heterogeneity according to his positivist research approach.

\section{Cultural heterogeneity of the MENA region}

In terms of geography, the region is home to several distinctive sub-regions, which can be further classified into North African countries (which includes Libya), the Levant countries (which includes Lebanon), the Middle East (which includes Egypt), and the Gulf States (which includes KSA, UAE, and Kuwait). The four distinct regions have their origins linked to historical division, geopolitics, and confederate alliances (Mahajan, 2012). Economically, the Gulf States, Kuwait, UAE, and KSA are 
classified as the richer counterpart to their neighboring countries. The value of the MENA region's GDP is approximately 3.6 trillion dollars, with the three Gulf States accounting for $37 \%$ of the GDP alone, with an average of one trillion and 300 billion dollars in GDP as of 2018 (World Bank Indicators, 2018). As such, they enjoy better economies thanks to their oil reserves and higher living standards than the remaining Arab States. However, it should be noted that the seven Arab States discussed above do differ in more than their geography and their political and economical history. Dialects within the region differ, as do clothing and common customs, such as music and literature. Such differences can affect how marketing efforts are employed in targeting and segmenting the region. For example, out of the sampled MENA countries, KSA has the highest market restrictions due to its strict adherence to the Islamic Law and Shari'a (Melewar et al., 2015). Even though in recent years KSA has undergone extensive changes in terms of socioeconomic reforms, such as the lifting of the ban on women driving, sponsored events where women and men freely mingle, and the introduction of movie theatres, it is still considered more restrictive than neighboring countries (Foley, 2019), ost notably the UAE, Iraq, Lebanon, and Egypt, in which public beaches are allowed, the selling and buying of alcohol is permitted, and discos and public dance clubs are the norm.

International firms find it more profitable and less risky when expanding into similar cultures. Countries have been grouped according to geographic proximity, religious commonalities, as well as social and psychological variables (Gupta et al., 2002). However, Hofstede has acknowledged that the region is not as homogenous as it was in the 1980s, the time he first surveyed the Arab States (Hofstede, 2001). This particular admission has shaped the objective of the present study, which is to reevaluate the Arab States rankings and investigate their differences or similarities based on Hofstede's dimensions, and its application to the international marketing field. The impact of geopolitical forces, religion, and similar historical backgrounds may have an impact on the cultural profiles of the MENA region, but that does not imply that geographic proximity is synonymous with cultural homogeneity (Kabasakal et al., 2012). Although MENA countries have commonalities in their social norms, they differ in relation to socioeconomic, ethnic, and demographic profiles. The MENA region is highly diverse with many ethnicities and a diverse range of economies and political systems (Mellahi et al., 2011). However, elaborating on their differences would be beyond the scope of this study. It should be noted that this article argues against the simplistic view of the regions' supposedly similar national cultures based on the existing cultural ranking of Hofstede's dimensions, and not necessarily against the concept of national culture itself. The aim of the study is to provide each Arab State with its own national culture identity for each dimension. As such, the VSM 13 was used to enable the current study to reassess each country on the six dimensions and to provide the literature with an un-clustered version of the region.

\section{METHODOLOGY}

The research instrument: the VSM13 
The Values Survey Module 2013 (VSM 13) questionnaire is a 30-item paper-based survey developed for comparing national differences and culturally influenced values of two or more countries (Hofstede et al., 2013). It includes questions and statements which are scored on both Likert and itemized scales. It computes answers on all previously mentioned six dimensions. Earlier versions of the VSM13 include the original edition of the instrument: the VSM80. The VSM80 sampled the cluster of the seven Arab States, but only tested them on four dimensions. That questionnaire was called the attitude survey module and was used solely for IBM HR purposes. The VSM 13 was never administered to the seven Arab States and neither were Hofstede's two newest dimensions, the long term/short term orientation and indulgence/restraint dimensions.

\section{Translating the VSM13}

Hofstede's latest version of his national culture questionnaire (the VSM13) has never been translated into Arabic, nor has it been administered in any Arab State. Hofstede et al. (2013) recommend that the VSM13 be translated by native speakers into their mother language and then employ a back translation as a safety device. As such, the VSM13 was translated by a professional Arabic translation agency and then retranslated into English by a different agency. The back translation assured consistent content meaning of items in both English and Arabic. Moreover, the Arabic version was pilot tested as well as compared with previous Arabic translations of earlier VSM editions to further uncover linguistic inconsistencies. After pre-testing the survey, the final version was sent to Hofstede, on his request, and rechecked for quality and accuracy. The Arabic version was deemed acceptable and was submitted by Hofstede to the Institute for Research on Intercultural Cooperation (IRIC) for distribution and was made available to other researchers. Furthermore, five management and two mathematics university professors from each respective Arab State were asked to look over the translation of the VSM 13, to conclude whether the questionnaire was clear enough to disseminate to students. After thorough examination, all professors remarked on the suitability of the Arabic version of the VSM 13. As for the clarity of the translation, many professors observed that the survey was translated in official Arabic, which is a universal language that is taught in all the surveyed Arab States, and is still the official language employed in government agencies and in the educational system throughout the region (Kabasakal et al., 2012).

Data collection method

For the present study, the data collection was dependent on the paper-based questionnaire survey. The research objective was to choose a matched sample from each Arab State to test for national differences between the countries by surveying them using the newly translated VSM13. Hofstede (2001) insists that comparisons between countries are based on samples that are matched on all criteria other than nationality so as not to affect the results of the questionnaire. The objective of the study is to survey a 
sample that can be found in each State and is sufficiently similar in age and educational background. Hofstede has previously sampled students when deriving his fifth dimension based on comparisons from students from 23 countries. As such, it was decided that universities were a rational choice, seeing as they would provide a closely matched sample that could conveniently be found in any country. Sampled students would also be similar in that they would not have been subjected to the influence of business culture and as such, students who have had part time jobs, or work experience, were automatically excluded, so as to provide the present study with the closest matched sample possible and to eliminate other institutional environmental effects, apart from national cultures. The researcher contacted several faculty members within each State to disseminate and administer the survey to their respective students in their classrooms. In total, 1400 surveys were disseminated to all the Arab States, 200 for each country. The final number of the participants came down to 775 students in total - 119 Libyan students, 130 Egyptian students, 121 Iraqi students, 104 Lebanese students, 90 Emirati students, 98 Saudi Arabian students, and 113 Kuwaiti students - an acceptable 55\% response rate.

VSM13 calculations

Due to the matched sample stipulation, scores attained by the VSM 13, or any VSM edition for that matter, cannot be used as a comparison tool with Hofstede's scores attained from the 1967 IBM survey. This is because the IBM sample took place in the 1970s, sampled IBM employees, and was conducted by a different instrument. Therefore, the VSM 13 survey manual suggests that for new replications or extensions to be considered valid they should be anchored to the old data set (Hofstede et al., 2013). This implies that any new scores computed by the VSM 13 should be added to the number derived from calculating the difference of the old and new data of the common country. This difference will represent a constant variable (C), which will be later added to the dimension's formula. However, in the case of the Arab States, there was no common country. To reiterate, the Arab States were clustered in the original survey and each country attained similar scores on all four respective dimensions. As such, there was no common or base country that could be used to find the difference between the old and new data sets, and therefore a constant could not be calculated. After corresponding with Hofstede, it was suggested that the averages for each country should be calculated for each dimension to act as a hypothetical base country. The hypothetical base country could then be used to find the difference between the old data scores. This difference will represent the constant (C), which should then be added to the formula to form the country's final score on the dimension. The scores are made so that they fall between $0-100$, but some samples may have scores that fall outside of the range (Hofstede, 2001).

VSM13 analysis

[insert table 1] 
Since Hofstede's theory is used for national level analysis, country level correlations will differ from individual level correlations. Therefore, when assessing the reliability of the VSM13, the overall mean scores of each country should be used. As such, all six dimensions utilized produced high Cronbach's alphas. It should be noted that Hofstede et al., (2013) suggest using a sufficient number of countries, usually more than thirty, so that further analysis of the questionnaire provides robust data. For example, the lack of mutual exclusivity of the dimensions has already been criticized in past literature (McSweeney, 2002). However, one wonders if attempts at further analysis will only yield similar poor results because of the small samples utilized, seeing as no past study replicating Hofstede's theory sampled more than 30 countries. In our case, we found our sample too small (seven countries) to conduct further confirmation of the factor structure required for confirmatory analysis, the data tested to confirm the underlying theory (Williams et al., 2010).

Selection of Arab States used in the study

In order for us to properly align our research with Hofstede's original study, we found the most plausible option was to conduct a cross-sectional study, because it would provide an appropriate snapshot of what the present study intends to investigate. This has also influenced the choice of sample, such that only the original Arab states that were sampled in 1967 were chosen. Our decision was influenced by our main objective which was to establish the differences between the Arab States that were originally indicated by Hofstede as broadly homogeneous, with no distinct cultural differences between them. We acknowledge that the MENA region is home to more cultural diversity than can be discerned in a study of the seven original states of Hofstede's study, ones with which there are clearly discernible differences such as between Qatar and Morocco, for example. However, as mentioned, our time constraints and resources were limited to the above mentioned seven Arab States. Moreover, we did not wish to achieve a comparison of our scores with Hofstede's 1967 scores, nor do we advocate that researchers seek to do so, seeing as this would not conform to the matched sample stipulation. What we wished to do was to empirically use Hofstede's own methodology to demonstrate differences according to the same theory that labelled the MENA region as being culturally homogeneous.

\section{FINDINGS}

After following Hofstede's recommended methodology, Table 2 shows the new scores for the Arab States, as follows:

[Table 2]

Power distance is the first dimension revealed by Hofstede's IBM data. The basic premise of the construct concerns the issue of human inequality and status consistency. Societies are measured on the basis of how much they expect and accept that power is distributed unequally. Inequalities come about 
because of disparities in wealth, power, and prestige, and how much weight is given to each area (Hofstede, 2001). According to Hofstede, high PDI societies encourage hierarchy, and thus inequality. Moreover, in high PDI societies, power does not need to be legitimate. The people in power are entitled to privileges, which in turn can foster corruption. The PDI dimension ranks Iraq, Libya, and Egypt as countries with very high power distance, while the Gulf States and Lebanon are ranked around average on the index. Hofstede has previously ranked MENA states as all having high power distance with a combined score of 80 . However, empirical results show a decrease in the power distance index's ranking among the Gulf States and Lebanon than previously theorized by Hofstede. The difference may be attributed to the exposure of these countries to other nations, especially Western countries, which has subsequently led to major social changes. For example, considerable wealth has been accumulated by the Gulf States because of the discovery of oil reserves in the 1990s, which has led to various business ventures and global trade agreements, exposing these societies to other cultures (Marsh, 2015). As such, the lower rankings of these countries may be taken as a byproduct of these countries' move from autocratic rulings to establishing constitutional monarchies with advisory councils, thereby lessoning the power of ruling families (Kabasakal and Bodur, 2002).

The second dimension relates to individual and collective aspects that are found in societies. Collective countries are more "we" conscious and are labeled as traditional societies. People are born into extended families and clans. Strong emphasis is placed on belonging to the group and identity derives from social systems that nurture members into the collective (Hofstede, 1994). The MENA region is known to embrace family cohabitation, in which children are encouraged and expected to live with their families even after reaching their adult age (Bowen and Early, 2002). In the Gulf region, in particular, individuals allocate two and sometimes three days a week to visit relatives and extended families (Marsh, 2015). Hofstede labelled the Arab States as collective with a combined rank of 38. However, even though our findings show that Arab States score more towards the collective end of the individualistic-collective spectrum, there is a disparity between their rankings. Empirical results rank KSA (48) and Lebanon (43) as being the highest on the individualism rank, but they still may be considered very collective when compared to other countries in the world, such as the highly individualistic USA. KSA's relatively high individualism rank compared to other Arab States may be attributed to it having the largest geographic size. It is not unusual to see families in the Kingdom sometimes split between different counties according to the location of their job or their university, thus minimizing time spent with family and friends. Kuwait (39), on the other hand, is considered the smallest country in terms of geographic volume and the most urbanized country within the Arab cluster, with highly populated cities and a strong Diwaniya culture. Diwaniya is a place, usually a room within a house, in which men receive visitors, such as family, friends, or business partners, and is seen as a phenomenon predominantly found only in the MENA region (Al-Nakib, 2016). The Diwaniya is a vital part of society where men can 
connect and discuss the news of the day uncensored by notions of gender propriety during these gatherings (Jones, 2008).

The third dimension pertains to the distribution of roles between the genders from which it derives its name: the masculinity-femininity construct. It should be noted that the index does not refer to equality between the genders, but which gender specific qualities are most expressed by the culture. Hofstede found that in highly masculine societies, people tend to value the opportunity for freedom and action. They prioritize attaining their own personal development and goals over the need to contribute to the welfare of others. Helping others, being of service, and demonstrating a nurturing aspect in one's personality is seen as constitutive of the femininity trait in societies. Considering the Arab States on the new index, we can see that Libya scores highest on the masculinity dimension (66 MAS). In Libya, although women enjoy equal status with men in the eyes of the law and have equal pay for equal work, as well as equal access to education, its society is still seen as being mainly male dominated (Jones, 2008). The social roles of the genders are fairly distinct, and there is not much overlap as seen in more feminine oriented countries, in which relationships play a vital role in society. On the other hand, KSA has the lowest ranking out of the cluster (43), which may be attributed to its society's emphasis on family and tribal affiliation, which is seen as the most important social institution in the country (Buchele, 2008). It should be noted that though KSA may be seen in the eyes of the media as a society that favors males and restricts women's rights, this is not so within the household. Whilst women in KSA do not participate in government affairs, they do take part in community events, fundraising activities, and social activities concerning Saudi society, and are considered to be the head of the household, extending their influence beyond their homes and family (Mahajan, 2012).

The fourth dimension describes how humans cope with the uncertainty of their future and is in essence their tolerance of (or lack of) ambiguity. Hofstede (1994) believes that the uncertainty avoidance construct primarily deals with society's need to protect itself from ambiguity through the utilization of technology, rules, and rituals. From this lens, high uncertainty avoidant societies will tend to have higher work stress, exhibit higher anxiety in its population, and face trust issues, especially regarding what they may believe to be foreign concepts. Hofstede had previously clustered the Arab States with a combined rank of 68 on the uncertainty avoidance scale. Our findings show Iraq to score highest on this dimension, at 96, with Egypt (at 55) scoring the lowest rank. It is not unusual to witness a high aversion to ambiguity and mistrust in Iraq's society, with its nation's long history of wars and tribulations. It was predicted that following the fall of Saddam Hussien's regime, Iraq would become a liberated, free, and democratic nation, an example to be followed by the MENA region, in terms of government and policy. However, the bubble soon burst, leaving the nation with the remnants of a once hopeful dream, to deal with the hard reality of war and death, shaping an extremely pessimistic and skeptical Iraqi culture (Zogby, 2010). Although Egypt also boasts a volatile history, it does not seem to have left its mark on 
its people, who are known throughout the MENA region for their resilience and good nature. They are often described as being friendly, cheerful, and humorous, despite having a substantial percentage of the population living in difficult conditions (Zogby, 2010). The concept of fatalism is also highly prevalent in Egypt, in which individuals deal with problems by saying that it is the will of Allah (Zayan, 2013). The adage "if life gives you lemons, then make lemonade" is exactly what Egyptians propose to do when life becomes difficult, and whereas this blasé attitude speaks of a careless nature and indifferent outlook on the future, it can also be considered a survival tactic.

Long term orientation versus short term orientation is the fifth dimension on Hofstede's national culture theory. It was conceived in 2001 and derived from answers of student samples from 23 countries on the Chinese Value Survey (CVS), first developed by Michael Bond (1988). The dimension was largely based on values relating to Eastern attitudes and values, in which its items represented prevalent Confucius teachings, such as persistence and thrift, as well as stability and respect for tradition. Long term oriented societies value investing, saving, and the achievement of results, while short term oriented societies value stability, traditions, conventions, and have a relatively small inclination to save. Hofstede (2001) attributed the absence of the dimension from his original set to the influence of the Western mindset when initially designing the IBM questionnaire. The Arab States were not originally surveyed by the CVS study and thus had no ranking on the fifth dimension. Our Arab State's ranking on the long term/short term dimension rank Iraq as the lowest (12) and Egypt with the highest score (42). Previous studies have shown Egyptians to be thrifty with an inclination to save rather than spend, unlike its neighboring Arab countries (Zayan, 2013). Difficult economic conditions and a large population could be taken as factors affecting Egypt's relatively high long term orientation's rank. Iraq, on the other hand, whilst undergoing a more unstable environment is shown to have a short term orientation. Despite the ramification of uninterrupted wars, Iraqis are more prone to think in terms of the present, perhaps due to the constant turmoil of ongoing conflicts (Hassan, 2015). The future is seen as uncertain with conditions perceived as unlikely to be positive. Only gratification in the present can lessen the burden of living in an unstable environment. Similarly, Rarick et al. (2014) have found that Iraqis are rather normative in their thinking and short term oriented. As a result, traditions and immediate results are valued more than saving for a future that is unlikely to improve.

Likewise, the sixth dimension, indulgence versus restraint, was not originally surveyed amongst the Arab States. The sixth construct was conceptualized in 2010 by Hofstede and Michael Minkov. The dimension relates to the drive for gratification versus the need to curb basic human desires related to the enjoyment of life (Hofstede, 2011). It is more or less thought to be a complementary construct to the long term/short term dimension, but was conceptualized from a different survey instrument, the World Values Survey (WVS), devised by sociologist Ronald Inglehart. According to Hofstede, a restrained society usually has a lack of freedom of speech, stricter sexual norms, and fewer happy 
people. In contrast, indulgent societies place more value on leisure time, are more likely to remember positive emotions, and freedom of speech is seen as paramount. From our empirical findings on the indulgence restraint dimension, Libya stands as the more indulgent country (74). Hofstede (2011) predicted that Muslim countries would fall within the restrained range, seeing as their faith would constrict them from gratifying what might be otherwise considered hedonistic pleasures. The Arab States all scored below the middle range which placed them as very restrained societies, validating Hofstede's claims, except for Libya (74). Libya is not known as a country that promotes free speech, something that is shared by many countries in the region; thus, Libya's highly indulgent rank is considered somewhat of an anomaly. However, it should be noted that the survey was disseminated to university students during Libya's transition from a dictator regime to a promised democratic and new nation. Therefore, it is hypothesized that Hofstede's index related items may have captured the optimism and elation that Libyans felt after the end of a long and hostile home regime. The ranking therefore becomes comprehensible, especially considering that the respondents were young students, optimistic and hopeful for a promising future.

\section{DISCUSSION}

The difficulty in gathering information about Arab consumers, and inefficient secondary data on MENA developing countries, tends to prompt international firms to adopt standardized strategies by grouping similar countries together based on macro commonalties (geographic, political, economic). Additionally, international firms may believe that the gap between modern MENA and Western societies is closing, and thus encourage the utilization of a standardized strategy in the region in terms of both managerial practices and segmentation strategies (Melewar et al., 2015). Standardization is also favored because it saves costs by taking advantage of potential synergies and economies of scale (Aaker and Joachimsthaler, 1999). A standardized approach in the MENA region may provide international firms with a consistent image across markets, facilitate cost reduction, and provide them with better control over the quality of their campaigns. However, Souiden (2002) argues that this does not reflect real market behavior, especially in the case of the MENA region, where variables such as GDP per capita may not reflect the actual level of purchasing power. As such, when international firms enter new markets, dependence on economic and demographic indicators alone cannot adequately predict a firm's entry success rates (Budeva and Mullen, 2014). In terms of managerial practices, employee interactions and organizational culture can have great implications in foreign markets, in which a lack of understanding towards the host culture can act as an impediment to the success of the firm (Hofstede et al., 2010 ). and

A review of international business studies which use culture to classify countries has led Vanderstraeten and Matthyssens (2008) to conclude that culture assessment studies are useful for both academics and practitioners. Increased trade between countries has meant that firms have had to increase their 
knowledge of different cultures and improve their organizational and marketing capacity to demonstrate cross-cultural sensitivity so as to better influence their target market and achieve more effective results. Firms are also required to understand the effects of culture on employee practices, interaction with managers from different cultures, and the most optimal alternative managerial theories and practices most relevant to the culture (Obeidat et al., 2012). Moreover, Papadopoulos and Martin (2011) believe that national values are considerably less researched within market selection literature, despite its importance in cross-cultural research and the fact that market selection is considered to be a major determinant of international performance. As such, we believe that national cultures are relevant to international firms because more companies are globalizing their operations, and management and business strategies are heavily influenced by cultural differences.

For example, Kuwait, which has a culture that is lower in power distance than neighboring countries such as Iraq and Libya, is considered more tolerant to Western influence and is known to accept the presence of Westerners (At-Twaijri and Al-Muhaiza, 1996). Kuwait also has a higher standard of living than other non-Western economies, and higher disposable incomes that have led to ostentatious lifestyles (Riquelme et al., 2011). Based on our findings, international firms interested in establishing trade ventures may see Kuwait's political system as more favorable, seeing as the climate is more open towards outside foreign investments. As such, joint ventures and franchising are currently the most prevalent and favored entry modes into the country (Mellahi et al., 2011). Al Shaya, one of the largest family-owned conglomerates, is considered to be the leading and largest retailing franchise company in the region, with licensing agreements with most major retail brands, such as Starbucks and Debenhams (Tytler, 2019; Mahajan, 2012). Powerful, often interconnected families may influence the sales of products and services and assist in getting licensing and production agreements necessary for manufacturing or regional distribution (Abbasi and Hollman, 1993). Establishing strong relationships with known society figures can also help eliminate difficulties associated with a firm's marketing activities and thus prove to be a competitive advantage against other international firms interested in targeting the region.

Moreover, power distance, along with uncertainty avoidance are considered the most relevant indices for organizational structure and behavior within an organization (Hofstede et al., 2010). For example, in high power distance and uncertainty avoidant countries such as Iraq (PDI 97, UAI 96), all the ideas and strategies emanate from the manager and every process is centralized. However, a centralized managerial style can lead to a greater absence of delegation of authority in addition to a lack of autonomy in lower level managerial positions (Obeidat et al., 2012). Additionally, personal relationships are also very important in which close subordinates to the manager enjoy certain privileges and can also act as advisers, which consequently might have resulted in the prevalence of nepotism in such countries (Kabasakal and Bodur, 2002). As such, formalized rules and strict imposed policies work 
best when managing employees from a similar national cultural profile (Robertson et al., 2002). Moreover, establishing strong friendships with host counter parts will more likely facilitate successful negotiations and business entreaties (Abbasi and Hollman, 1993). However, we note that countries that are lower in uncertainty avoidance and power distance, such as Lebanon (PDI 62, UAI 57), are more accepting of contrary managerial practices. According to Yahiaoui and Al Ariss (2017), Lebanon is rich in terms of human resources but lacks the natural resources needed for economic development. This makes the Lebanese more entrepreneurially oriented and thus more tolerant of risk, which is empirically congruent with their higher individualistic ranking as opposed to their clustered 1967 collective score. They are also more liberal given their extensive interaction with non-Arabs around the Mediterranean and thus more accepting of foreign managerial practices. This is in part due to immigration and extensive travel for trade ventures by the Lebanese, which has traditionally been motivated by improving the standard of living of one's family (Yasin and Zimmerer, 1995).

Likewise, communication is seen as one of the most important factors necessary for the success of any firm looking to compete and work in an international setting (Tian and Borges, 2011). For example, consumers favor advertising messages and appeals that are congruent with their cultural values and thus, the use of adapted and localized marketing campaigns that promote the national culture of the targeted country enable a firm's marketing communication to be more effective (Chang, 2006). In determining differences in cultures, international marketers could better formulate their international marketing communication strategies and avoid having the intended target market misunderstand the firm's intended messages (Elbashier and Nicholls, 1983). In particular, and we find that the individualism index has an impact on advertising appeals, such that emotional advertising may not work as well as rational advertising in highly individualistic countries (Rossiter and Percy, 1987). Advertising appealing to individualistic countries should stress the exclusivity of the product or service and its uniqueness. On the other hand, we have noted that short oriented and uncertainty avoidant societies, such as KSA (LTO 27, UAI 64), prefer advertising that creates trust and being a part of one's traditions, a constant that is both reassuring and reliable. They also favor the opinion of experts and more informative advertising, and are less accepting of youthful messages as the younger generation is seen as untrustworthy. However, utilizing similar communication strategies may not be suitable for the Egyptian market, which is now ranked as the lowest uncertainty avoidant country in the sample and as such is more comfortable with ambiguity and prefers to be entertained rather than informed. Mai Azmy, managing director of JWT Cairo confirms, 'Egyptians are exposed to a lot of clutter and they're looking for entertainment' (Beattie, 2015). Egypt also has a young population which responds more to advertising that features young adults, incorporates humor, and features well known celebrities (ElGharbawy, 2015)This responds well to their masculine culture (MAS 55), which values achievement, since an idealistic social figure involvement can help Egyptians relate to the product and believe that by adopting the product, they will be similar and closer to their idols. They are also the highest ranked 
on the long term orientation index (LTO 42), such that new data indicate that Egyptians are focusing more on the price of the products they buy and are shifting away from luxury items (Nielsen, 2018). As such, hedonic promotional activities directed at Egypt's more frugal consumers may not work as well as they would for short oriented and high power distance countries, such as Kuwait (LTO 19, PDI 73), in which individuals have a low inclination to save and status items are more valued. Based on our findings and Kuwait's power distance ranking, we find that luxury brands can play an important role in communicating the importance of an inherently conservative status quo in Kuwait more so than in Egypt.

Communication can also refer to the ways in which the international firm communicates with their host managers and employees. For example, the individualism index can also be used to infer work related values, such that high individualistic countries tend to be more oriented towards achieving their tasks over nurturing relationships in the work place. It is true that most of the Arab States scored collective on our new ranking, and while it does extend and validate Hofstede's original claim of the region's tribal collectivism, it also provides country specific rankings on the index - a need that has been cited in the literature as necessary towards understanding cross-cultural behavior (Whiteoak et al., 2006). For instance, when combining KSA's higher MAS and IDV index (MAS 43, IDV 48), we believe that international firms should emphasize promotion opportunities and recognize individual efforts and performance when dealing with host managers. Moreover, managers should be aware that short oriented and restrained cultures such as Kuwait (LTO 19, IVR 29) are more inclined to be very fatalistic and concentrate more on short term goals, expressing such sentiments in sayings like "Insh Allah" or God willing, when referring to future tasks (Yasin and Zimmerer, 1995). Hofstede (2001) seems to believe that religion can play an indicative role as to what level the Arab States' ranking will be on the LTO dimension. It is necessary to allude to the fact that both culture and religion are intertwined in the region and are difficult to divorce in both practice and theory (Patai, 1952). As such, Robertson et al. (2002) recommend that international managers should be informed of the strong relationship between religion and work ethics in the region. However, even if Islam is still considered a unifying cultural aspect for the region, then it should be noted that Muslims all over the world, and even Muslim Middle Easterners, differ on every aspect, such as geography, class, customs, and ethnicity (Bowen and Early, 2002). The MENA region is dominated by Islam, but different sects do exist and their dominance varies across countries (Kabasakal et al., 2012).

In addition, culture also plays a part in influencing consumer behavior in the area of distribution in which the cultural orientation of consumers can help establish and support small retailers through vendor loyalty (Tian and Borges, 2011). As such, international firms targeting highly collective societies, such as Iraq and Libya, should support local distributors and engage in certain culturally bound channel structures, such as bazaars or local stores. From a relationship perspective, well nurtured 
networks are considered essential, in part due to the cost savings associated with keeping a current client as opposed to winning a new one (Samiee et al., 2015). Well nurtured networks are considered essential in high UAI and collective countries, such that family and relatives tend to be the favored choice for business partners and employees (Bradley et al., 2010). As such, developing quality relationships reduces potential risks in doing business in unchartered regions, especially when the environment is averse to connections to unknown entities. In highly collective societies, such as Iraq (IDV 31), finding a partner is important, and potential partners are usually family owned businesses where financial resources are great and prominent individuals have great political clout and can ensure rapid dissemination of their partner's brand throughout the country. Moreover, there are certain aspects of particularism in collective societies where relationships prevail over task orientations and as such, foreign firms need to be aware of the existence and prevalence of nepotism in organizations working in such cultures, especially when coupled with a high power distance ranking (Hofstede et al., 2010).

Numerous past studies have detailed the differences between Eastern and Western markets in terms of international strategies and managerial practices (Al-Olayan and Karande, 2000; Kabasakal and Bodur, 2002; Melewar et al., 2015). The existing literature is prevalent in research comparing Western culture with Eastern culture, a legacy of the Western tradition of Orientalism that developed in Western societies in the eighteenth century (Said, 1978). It paints the Middle East as a largely cohesive region with a unifying identity. The region does appear, on the surface at least, as one cluster; however, that is in part due to the researchers' approach of comparing the MENA region against other culturally similar clustered areas such as in Europe or East Asia. We believe it is time that the MENA region is dissected and compared against itself. The empirical differences we found are indicative of a multicultured region. Regardless of their similar common language, religion, and geographical location, the Arab States consistently registered differences on all of Hofstede's dimensions. This demonstrates that what appears to be culturally homogenous on the surface may not prove to be so when dealing with markets. Consequently, similar broad macro country characteristics may not mean similar market behavior and there is no guarantee that a brand that is successful in Dubai will be so in Riyadh (Jones, 2003).

\section{CONCLUSION}

Levitt's (1993) provocative study proposes that differences in culture and national taste are a thing of the past, and though he acknowledges that systematic national differences exist by citing the enormous differences found among the Middle Eastern countries, he nevertheless asserts that with enough time and effort they can be overcome by multinational firms. We reason that 35 years later, this culture hurdle has yet to be crossed, particularly in relation to the MENA region. We believe that culture affects the degree to which international firms can adapt or standardize their marketing communication strategies in other countries, as well as affect the choice of appropriate managerial practices when dealing with host employees and managers. We believe our findings provide empirical evidence for the 
differences found in the Arab States' national cultures. In the case of the Arab States, there are a low number of local studies, especially in Iraq and Libya, mainly due to economic and political sanctions, in addition to wars and civil unrest. Lack of data may sometimes force international firms to adopt new ways to estimate market potential in Arab States. As such, we believe our investigation into the national cultures of the MENA region can supplement such estimates and provide an important source of understanding of the cultural differences that exist within Arab markets. As a result, we believe that marketing strategies in the MENA region can be better informed with our new national culture indices.

Many marketing and management theories have been developed in Western societies. It is imperative that they are tested and validated in other societies so that their degree of generalizability and applicability can be ascertained. As such, one of the key theoretical contributions of this study is the extension and validation of Hofstede's theory in the context of international marketing and management. An enhanced empirical understanding of the MENA region's national culture profiles is a further important and pioneering contribution. The present study is the first attempt to empirically uncluster Hofstede's original Arab States' sample using both Hofstede's own methodology and personal assistance, thereby negating assumptions of a homogenous Arab national culture and region. As such, the present study also provides international firms with updated figures for comparison and a better understanding of the region's national culture and its implications and potential for international firms. A review of the literature reveals that there is a scarcity of studies that investigate the national cultures of Arab States due to Hofstede's initial claim of their unified culture (Alajmi et al., 2011). The argument put forward by the present study does not intend to negate the importance of other variables relevant to international business but attempts to supplement them and emphasize the importance of distinguishing the Arab States' national cultures and the implications that this has for international firms. As such, the present study can be extended to include more countries other than the MENA region to provide a better comparison of different national cultures. Finally, additional consumer behavior studies and crosscultural investigations are highly recommended for international firms committed to substantial involvement in the MENA region. These further recommendations notwithstanding, it is hoped that this paper sensitizes scholars to the importance of the MENA region's distinctive national cultures and opens up valuable avenues for further research and investment. 
Table 1 Reliability results

\begin{tabular}{|c|c|c|c|c|c|}
\hline Factor & Items & Mean & Std. Deviation & $\begin{array}{c}\text { Cronbach's } \\
\text { alpha }\end{array}$ & $\begin{array}{c}\text { Item to } \\
\text { Total } \\
\text { Correlation }\end{array}$ \\
\hline \multirow{4}{*}{$P D I$} & Q07 & 2.9386 & .59759 & \multirow{4}{*}{.920} & .962 \\
\hline & Q02 & 3.0829 & .53310 & & .970 \\
\hline & Q20 & 3.2043 & .34818 & & .497 \\
\hline & Q23 & 2.9529 & .72263 & & .953 \\
\hline \multirow{4}{*}{$U A I$} & Q18 & 2.8614 & .64623 & \multirow{4}{*}{.889} & .957 \\
\hline & Q15 & 3.1586 & .53530 & & .972 \\
\hline & Q21 & 2.9329 & .15327 & & .286 \\
\hline & Q24 & 3.1586 & .58193 & & .956 \\
\hline \multirow{4}{*}{$I D V$} & Q04 & 2.5943 & .69120 & \multirow{4}{*}{.991} & .998 \\
\hline & Q01 & 2.6729 & .74121 & & .995 \\
\hline & Q09 & 2.8829 & .62646 & & .991 \\
\hline & Q06 & 2.5971 & .54273 & & .961 \\
\hline \multirow{4}{*}{$M A S$} & Q05 & 2.3014 & .45922 & \multirow{4}{*}{.968} & .837 \\
\hline & Q03 & 2.5500 & .62934 & & .995 \\
\hline & Q08 & 2.9686 & .76517 & & .959 \\
\hline & Q10 & 2.6729 & .64838 & & .979 \\
\hline \multirow{4}{*}{ LTO } & Q13 & 2.9557 & .70225 & \multirow{4}{*}{.981} & .975 \\
\hline & Q14 & 3.0857 & .45471 & & .980 \\
\hline & Q19 & 2.5343 & .67270 & & .980 \\
\hline & Q22 & 2.6286 & .74104 & & .973 \\
\hline \multirow{4}{*}{$I V R$} & Q12 & 2.8029 & .31569 & \multirow{4}{*}{.944} & .892 \\
\hline & Q11 & 2.7629 & .62641 & & .939 \\
\hline & Q17 & 3.1971 & .43626 & & .956 \\
\hline & Q16 & 3.1071 & .59019 & & .965 \\
\hline
\end{tabular}


Table 2 New dimension Scores

\begin{tabular}{|c|c|c|c|c|c|c|c|c|}
\hline & $\begin{array}{c}\text { Arab } \\
\text { Cluster } \\
\text { in } 1967\end{array}$ & Kuwait & KSA & UAE & Lebanon & Iraq & Egypt & Libya \\
\hline PDI & $\mathbf{8 0}$ & 73 & 72 & 74 & 62 & 97 & 80 & 103 \\
\hline IDV & $\mathbf{3 8}$ & 39 & 48 & 36 & 43 & 31 & 37 & 35 \\
\hline MAS & $\mathbf{5 2}$ & 45 & 43 & 52 & 48 & 53 & 55 & 66 \\
\hline UAI & $\mathbf{6 8}$ & 70 & 64 & 66 & 57 & 96 & 55 & 67 \\
\hline LTO & N/A & 19 & 27 & 22 & 22 & 12 & 42 & 15 \\
\hline
\end{tabular}




\section{References}

A.M. Elbashier and J.R. Nicholls. 1983. Export Marketing in the Middle East. The Importance of Cultural Differences. European Journal of Marketing, 17(1): 68-81.

Aaker, D.A. and Joachimsthaler, E. 1999. The lure of global branding. Harvard business review, 77(6): pp.137-44.

Abbasi, S. M. and Hollman, K. W. 1993. Business success in the Middle East. Management Decision, 31(1).

Alajmi, S., Dennis, C. and Altayab, Y. 2011. The effect of national culture on service provision within Takaful industry: A comparative study in Kuwait and Egypt. Journal of Islamic Marketing, 2(3): 225245.

Al-Nakib, F. 2016. Kuwait transformed: a history of oil and urban life. Stanford University Press.

Al-Olayan, F.S. and Karande, K., 2000. A content analysis of magazine advertisements from the United States and the Arab world. Journal of Advertising, 29(3), pp.69-82.

At-Twaijri, M. I. and Al-Muhaiza, I. A. 1996. Hofstede's cultural dimensions in the GCC countries: An empirical investigation. International Journal of Value-Based Management, 9(2): 121-131.

At-Twaijri, M.I. 1989. A cross-cultural comparison of American-Saudi managerial values in US-related firms in Saudi Arabia: An empirical investigation. International Studies of Management and Organization, 19(2): 58-73. Not in text?

Bakel, M. V. 2002. In collision with the iceberg called culture. Gender, Transcience and Identity. Oxford: University of Oxford Not in text?

Baskerville-Morley, R. F. 2005. A research note: the unfinished business of culture. Accounting, Organizations and Society, 30(4): 389-391.

Beattie, Anita. Adage. 2015. Is Egypt the world's most underrated market? http://adage.com/article/global-news/egypt-world-s-underrated-market/297711. Accessed July 92018.

Beugelsdijk, S., Kostova, T. and Roth, K. 2017. An overview of Hofstede-inspired country-level culture research in international business since 2006. Journal of International Business Studies, 48(1): 30-47.

Bond, M. H. 1988. Finding universal dimensions of individual variation in multicultural studies of values: The Rokeach and Chinese value surveys. Journal of personality and social psychology, 55(6): 1009. 
Bowen, D.L. and Early, E.A. eds., 2002. Everyday Life in the Muslim Middle East. Indiana University Press.

Bradley III, D.B., Brown, J.E. and Rubach, M.J. 2010. IRAQI BUSINESS CULTURE: AN EXPATRIATE'S VIEW. Journal of International Business Research, 9(2).

Buchele, N. 2008.Saudi Arabia-Culture Smart!: The Essential Guide to Customs and Culture. Kuperard.

Budeva, D.G. and Mullen, M.R. 2014. International market segmentation: Economics, national culture and time. European Journal of Marketing, 48(7-8): pp.1209-1238.

Caprar, D. V., Devinney, T. M., Kirkman, B. L. and Caligiuri, P. 2015. Conceptualizing and measuring culture in international business and management: From challenges to potential solutions. International Journal of Business Studies, 46: 1011-1027.

Chang, C. 2006. Seeing the small picture: Ad-self versus ad-culture congruency in international advertising. Journal of Business and Psychology, 20(3): pp.445-465.

Clark, T. 1990. International marketing and national character: A review and proposal for an integrative theory. Journal of Marketing, 54(4).

De Mooij, M., and Hofstede, G. 2010. The Hofstede Model: applications to global branding and advertising strategy and research. International Journal of Advertising, 29(1): 85.

El-Gharbawy, A. 2015. The Impact of Social Advertising Campaigns in Shaping Egyptian Youth's Behavioral Intentions. In Marketing Dynamism and Sustainability: Things Change, Things Stay the Same... (pp. 141-152). Springer, Cham

Foley, S. 2019. Changing Saudi Arabia: Art, Culture, and Society in the Kingdom. Lynne Rienner Publishers, Incorporated.

Gupta, V., Hanges, P. J. and Dorfman, P. 2002. Cultural clusters: Methodology and findings. Journal of world business, 37(1): 11-15.

Hall, E. T. 1976. Beyond culture. New York: Anchor Books.

Haller, M., 2002. Theory and method in the comparative study of values: Critique and alternative to Inglehart. European sociological review, 18(2), pp.139-158.

Hassan, S. 2015. The influence of national culture on international marketing and consumer behaviour in Iraqi Kurdistan, using Hofstede's model at individual level. British Journal of Marketing Studies, 3(8): 50-78. 
Hofstede, G. 1994. The business of international business is culture. International business review, 3(1): $1-14$.

Hofstede, G. H. 2001. Culture's consequences: Comparing values, behaviours, institutions and organizations across nations. Sage Publications

Hofstede, G. 2011. Dimensionalizing cultures: The Hofstede model in context. Online readings in psychology and culture, 2(1): 8.

Hofstede, G., Hofstede, G. J. and Minkov, M. 2010. Cultures and Organizations: Software of the Mind. Revised and expanded 3rd Edition. N.-Y.: McGraw-Hill.

Hofstede, G. 2013. Replicating and extending cross-national value studies: Rewards and pitfalls-An example from Middle East studies. Academy of International Business Insights, 13(2): 5-7.

Hofstede, G., Hofstede, G.J., Minkov, M. and Vinken, H. 2013. Values survey module 2013 manual. Maastricht: Institute for Research on Intercultural Cooperation.

House, R. J, Hanges, P. J., Javidan, M., Dorfman, P. W. and Gupta, V. 2004. Culture, leadership, and organizations, (pp. 9-28). California: Sage publications.

Inglehart, R. 2000. Globalization and postmodern values. Washington Quarterly, 23(1): 215-228.

Inkeles, A. and Levinson, D. J. 1969. National character: The study of modal personality and sociocultural systems. The handbook of social psychology, 4: 418-506.

Jones, G. 2003. Middle East expansion-the case of Debenhams. International Journal of Retail and Distribution Management, 31(7): 359-364.

Jones, R. 2008. Libya-Culture Smart!: The Essential Guide to Customs and Culture. Kuperard.

Kabasakal, H. and Bodur, M. 2002. Arabic cluster: a bridge between East and West. Journal of World Business, 37(1): 40-54.

Kabasakal, H., Dastmalchian, A., Karacay, G. and Bayraktar, S. 2012. Leadership and culture in the MENA region: An analysis of the GLOBE project. Journal of World Business. 47(4): 519-529.

Leung, K., Bhagat, R. S., Buchan, N. R., Erez, M. and Gibson, C. B. 2005. Culture and international business: Recent advances and their implications for future research. Journal of international business studies, 36(4): 357-378. 
Levitt, T. 1993. The globalization of markets. Readings in international business: a decision approach, 249.

Lynn, M. and Gelb, B.D., 1996. Identifying innovative national markets for technical consumer goods. International Marketing Review.

Mahajan, V. 2012. The Arab World Unbound: Tapping in to the Power of 350 Million Consumers. San Francisco: John Wiley and Sons, Inc.

Mahmoud M. Yasin and Thomas Zimmerer, 1995. Achieving new venture success in the emerging Arab countries: a study of comparative cultures and strategies in two segments of the Arab world. Cross Cultural Management: An International Journal, 2(4): 3-14

Marsh, D. 2015. Doing Business in the Middle East: A cultural and practical guide for all Business Professionals. Robinson

McSweeney, B., 2002. Hofstede's model of national cultural differences and their consequences: A triumph of faith-a failure of analysis. Human relations, 55(1), pp.89-118.

McSweeney, B. 2013. Fashion founded on a flaw: The ecological mono-deterministic fallacy of Hofstede, GLOBE, and followers. International Marketing Review, 30(5): 483-504.

Melewar, T.C., Turnbull, S. and Balabanis, G. 2000. International advertising strategies of multinational enterprises in the Middle East. International Journal of Advertising, 19(4): 529-547.

Mellahi, K., Demirbag, M. and Riddle, L. 2011. Multinationals in the Middle East: Challenges and opportunities. Journal of World Business, 46(4): 406-410.

Ng, S.I., Lee, J.A. and Soutar, G.N., 2007. Are Hofstede's and Schwartz's value frameworks congruent?. International marketing review.

Nielsen, 2018. http://www.nielsen.com/eg/en/insights/news/2017/redefining-egyptian-consumers-inthe-current-climate.html. Accessed July 122018.

Obeidat, B. Y., Shannak, R. O., Masa'deh, R. E. M. D. T. and Al-Jarrah, I. 2012. Toward better understanding for Arabian culture: Implications based on Hofstede's cultural model. European Journal of Social Sciences, 28(4): 512-522.

Papadopoulos, N. and Martín Martín,O. 2011. International market selection and segmentation: perspectives and challenges. International Marketing Review, 28(2): 132-149.

Patai, R. 1952. The Middle East as a culture area. Middle East Journal, 6(1): 1-21. 
Patel, T., 2013. Cross-cultural Management: A transactional approach. Routledge.

Peterson, M.F., 2007. The heritage of cross cultural management research: Implications for the Hofstede chair in cultural diversity. International Journal of Cross Cultural Management, 7(3), pp.359-377.

Rarick, C., Winter, G., Barczyk, C. and Merkt, E. 2014. Iraqi and Kurdish Cultural Values in the SemiAutonomous State of Kurdistan. Global Journal of Management and Business Research, 14(3).

Riquelme, H.E., Rios, R.E. and Al-Sharhan, N., 2011. Antecedents of ostentatious consumption in Kuwait. Journal of Islamic Marketing.

Robertson, C. J., Al-Khatib, J. A. and Al-Habib, M. 2002. The relationship between Arab values and work beliefs: An exploratory examination. Thunderbird International Business Review, 44(5): 583-601.

Rossiter, J.R. and Percy, L. 1987. Advertising and promotion management. McGraw-Hill Book Company.

Said, E. 1978. Orientalism: Western representations of the Orient. New York: Pantheon.

Samiee, S., Chabowski, B.R. and Hult, G.T.M. 2015. International relationship marketing: Intellectual foundations and avenues for further research. Journal of International Marketing, 23(4): 1-21.

Schwartz, S. H. 1994. Are there universal aspects in the structure and contents of human values?, Journal of social issues, 50(4): 19-45.

Schwartz, S. H. 2006. A theory of cultural value orientations: Explication and applications. Comparative sociology, 5(2): 137-182.

Singh, S. 2006. Cultural differences in, and influences on, consumers' propensity to adopt innovations. International Marketing Review, 23(2): 173-191.

Smith, P.B., Dugan, S. and Trompenaars, F., 1996. National culture and the values of organizational employees: A dimensional analysis across 43 nations. Journal of cross-cultural psychology, 27(2), pp.231-264.

Søndergaard, M. 1994. Research note: Hofstede's consequences: a study of reviews, citations and replications. Organization studies, 15(3): 447-456.

Souiden, N. 2002. Segmenting the Arab markets on the basis of marketing stimuli. International Marketing Review, 19(6): 611-636.

Takada, H. and Jain, D. 1991. Cross-National Analysis of Diffusion of Consumer Durable Goods in Pacific Rim Countries. Journal of Marketing, 55(2). 
Tian, K. and Borges, L. 2011. Cross-cultural issues in marketing communications: An anthropological perspective of international business. International Journal of China Marketing, 2(1): 110-126.

Triandis, H. C. 2004. The many dimensions of culture. The Academy of Management Executive, 18(1): $88-93$.

Trompenaars, F. and Hampden-Turner, C. 1998. Riding the waves of culture, New York: McGraw-Hill. Tytler, J., 2019. Merchants and Princes in Kuwait and Dubai.

Van Everdingen, Y. M. and Waarts, E. 2003. The effect of national culture on the adoption of innovations. Marketing Letters, 14(3): 217-232.

Vanderstraeten, J. and Matthyssens, P. 2008. Country classification and the cultural dimension: a review and evaluation. International Marketing Review, 25(2): 230-251.

Whiteoak, J. W., Crawford, N. G. and Mapstone, R. H. 2006. Impact of gender and generational differences in work values and attitudes in an Arab culture. Thunderbird International Business Review, 48(1): 77-91.

Williams, B., Brown, T., and Onsman, A. (2010). Exploratory factor analysis: A five-step guide for novices. Australasian Journal of Paramedicine, 8(3)

Williamson, D., 2002. Forward from a critique of Hofstede's model of national culture. Human relations, 55(11), pp.1373-1395.

World Bank. 2018. World Development Indicators Online (WDI) database. Accessed Jan 30, 2020.

Yahiaoui, D. and Al Ariss, A. 2017. Diversity in the Arab World: Challenges and Opportunities. In Management and Diversity: Perspectives from Different National Contexts (pp. 249-260). Emerald Publishing Limited.

Yasin, M.M. and Zimmerer, T. 1995. Achieving new venture success in the emerging Arab countries: a study of comparative cultures and strategies in two segments of the Arab world. Cross Cultural Management: An International Journal, 2(4): pp.3-14.

Zayan, J. 2013. Egypt-Culture Smart!: The Essential Guide to Customs and Culture. Bravo Limited. Zogby, J. 2010. Arab voices: what they are saying to us, and why it matters. St. Martin's Press. 